\title{
The Impact of Emotional Intelligence on Enhancing Women's Leadership Competencies
}

\author{
Samira Shabani ${ }^{1}$, Fadil T. Çitaku ${ }^{1,4}$, Hetem Ramadani ${ }^{1,2}$, Max S. Mano ${ }^{1,3}$, Paul Barach ${ }^{1,7}$, Marianne Waldrop ${ }^{1,4}$, \\ Don Zillioux ${ }^{1,4,6}$ \& Yawar Hayat Khan ${ }^{1,5,6}$ \\ ${ }^{1}$ Academy of Leadership Sciences Switzerland, Switzerland \\ ${ }^{2}$ Health Revolution, Albania \\ ${ }^{3}$ Hospital Sírio-Libanês, São Paulo, Brazil \\ ${ }^{4}$ Strategic Development Worldwide, USA \\ ${ }^{5}$ RAK College of Dental Sciences, UAE \\ ${ }^{6}$ Riphah International University, Islamabad, Pakistan \\ ${ }^{7}$ Wayne State University School of Medicine, USA \\ Correspondence: Samira Shabani, Academy of Leadership Sciences Switzerland, Switzerland. E-mail: \\ samiramshabani@gmail.com
}

Received: August 14, 2021

doi:10.5539/ijbm.v16n11p105
Accepted: September 16, $2021 \quad$ Online Published: October 20, 2021

URL: https://doi.org/10.5539/ijbm.v16n11p105

\begin{abstract}
The percentage of women in leadership positions is increasing and advancing towards gender parity. However, the number of female leaders is still low when compared to male leaders. We endeavored to examine by means of a literature review the impact of Emotional Intelligence (EI) on women's leadership since we found that EI is a key factor in predicting effective leadership traits. We also found there is a social perception that women tend to be seen as more emotional and empathic than men. We review the definitions of leadership and EI and explore the link between EI, leadership and women. Several leadership scholars and psychologists argue that EI is an important foundation for leadership effectiveness. We review the literature about how men and women compare in their EI attributes. When it comes to learning EI, men and women have the same opportunities to acquire a greater EI through reflection and experience. However, we highlight the necessity for increasing the number of women in leadership positions by enhancing and supporting women's leadership competencies. Moreover, we emphasize the importance of building EI in order to achieve effective leadership.
\end{abstract}

Keywords: emotional intelligence, leadership, women leadership, leadership competencies, transformational leadership

\section{Introduction}

The nineteenth century marked the rise of leadership studies (Grint 2011) when authors, such as Carlyle (1872) began exploring which characteristics qualified the great men in history to become competent and effective leaders. The research resulted in the "Great Man Theory", and then, in the Leadership Trait Approach, which identified leadership as inborn competencies (Khan et al., 2016). According to this theory, leaders were born with personality traits that would explain their leadership positions. Mann (1959) defined six characteristics describing effective leadership including: intelligence, masculinity, dominance, adjustment, extraversion, and conservatism. After reconsidering Mann's findings, Lord and his associates (1986) intelligence, masculinity, and dominance as essential leadership traits. While examining the characteristics of effective leaders, these researchers emphasised masculinity as an important attribute. However, these insights are in contradiction to today's wider and "increasingly sophisticated" (Grint, 2011,p. 11) understanding of leadership. Hence, rather than just personal traits that define an effective leader, it is, for example, their behaviour, their ability to be authentic as well as the context in which they act (Debele, 2019). Additionally, successful female leaders have demonstrated that femininity as well can function as a trait of effective leadership. Whether in the political world - where Finland designated the 34 years old Sanna Marin as prime minister with a cabinet largely composed of women (Harrison, 2019), or in the social sphere where Mother Theresa was held up as a contributor to humanity by helping poor, sheltered and 
suffering people (Bolton, 2020). Therefore, several scholars (Carli \& Eagly, 2011; Eagly et al., 1992; Foss et al., 2021) started examining the role of women in leadership positions, their contribution to innovation and effectiveness as well as the leadership style they exhibit. However, since women in leadership positions are still a minority compared to men, a number of articles (Eagly et al., 1992; Ruderman et al., 2002) address possible disadvantages women face when it comes to these positions.

The research on identifying effective leadership has changed and is experiencing a major revision. Researchers today acknowledge that leadership competencies are not innate and that they can be learned by men and women alike (Northouse, 2010). Moreover, masculinity by itself is no longer viewed as a trait that is positively related to leadership. Instead, Emotional Intelligence (EI) is considered as one of the fundamental qualifications for effective leadership (Goleman, 1998). This insight challenges the Trait Approach since, first, EI is not fixed and can be acquired and improved. Second, according to gender stereotypes, women display higher levels of empathy and interpersonal skills (Loeffler \& Greitemeyer, 2021), both important elements that contribute to EI. This leads to a stereotyped perception by society that women have more EI than men (Fernández-Berrocal, 2012). Consequently, the following literature review will discuss the question of whether EI impacts and enhances Women's Leadership Competencies.

\section{Defining Leadership and EI}

\subsection{Leadership}

Researchers acknowledge the necessity for competent leaders and indeed the threat and dangers of incompetent leaders has been acknowledged for the main reason why some countries have weathered COVID effectively and others have failed like the US and UK (Walker, 2020). Whether in politics, business, or in everyday life, a leadership style determines performance and success. While the engagement with leadership dates back to ancient philosophers such as Aristotle and Plato (Toor \& Ofori, 2008), the research on effective leadership has made its greatest progress in the twentieth century. In the 1960s, the trait approach focused on the traits possessed by leaders, while the skills approach placed the emphasis on skills and abilities that can be learned and developed (Northouse, 2010). According to the trait approach, the leader's personality and inborn characteristics were decisive for leadership effectiveness (Khan et al., 2016). Over the years the research on leadership approaches has been expanded and deepened. Today, researchers acknowledge that the personality of a leader as well as the relationship the leader and the group are operating under are decisive for effective leadership (Çitaku et al., 2012). Leadership is considered a co-produced process in which an individual influence another individual or a group of individuals to achieve a common goal (Çitaku et al., 2012). The fundamental elements of this leadership model are the leader, group or followers, influence, and the existence of a common goal. This leadership process is available to everyone and each individual can learn the necessary capabilities for effective leadership.

A variety of other leadership approaches exist and aim to prescribe effective leadership processes. Two examples are the Authentic and the Transformational Leadership approaches which argue that demonstrating ethical behavior and personal character, authentic transformational leaders accomplish the most impressive of leadership challenges. They lead their followers through risk taking, personal development and organizational change. The Authentic Leadership theory resulted from research on enhancing positive leadership and focusses on authenticity, and consequently, on the reliability and sincerity of leaders (Luthans \& Avolio, 2003). The Transformational Leadership theory is engaged with the changes that occur during the leadership process and aims to achieve lofty outcomes by influencing subordinates to achieve greater results than what was believed possible (Schaubroeck et al., 2007). These two approaches concentrate on the interaction between leader and subordinates which is dominated by factors such as inspiration and motivation, moral standards (Bass \& Steidlmeier, 1999), coaching by listening, transparency, and self-awareness. Leadership intends to achieve a collective objective of raising subordinates' potential to its fullest, and is supported by strong ethical foundation (Northouse, 2010). Bennis and Nanus (1985) posit that leaders are people who do the right thing.

\subsection{Emotional Intelligence}

Several leadership approaches highlight the significance of emotional involvement. Mayer and Caruso (2002) content that EI aims at understanding and using emotional information related to social relationships and maintain that "EI, refers to the capacity to understand and explain emotions, on the one hand, and of emotions to enhance thoughts, on the other" (p. 2). Daniel Goleman, however, was concerned with defining and explaining the notion of EI and argued that there are five factors that determine EI (figure 1).

The first factor is self-awareness. This trait enables people to recognise their emotions and feelings and the reason for their existence. Moreover, self-awareness facilitates our decision-making process and increases our intuition (Goleman, 2003) which includes three emotional competencies (Mayer \& Caruso, 2002). First, emotional 
competence as reported by Goleman is emotional awareness. This ability enables individuals to perceive their own emotions and the impact that these emotions have on their actions (Goleman, 2003). Second, accurate self-assessment ensures that individuals are aware of their inner resources, hence, of their capabilities, strengths, and weaknesses (Goleman, 1998). Finally, the emotional competence self-confidence requires a keen understanding and insight into one's abilities and limitations (Goleman, 1998).

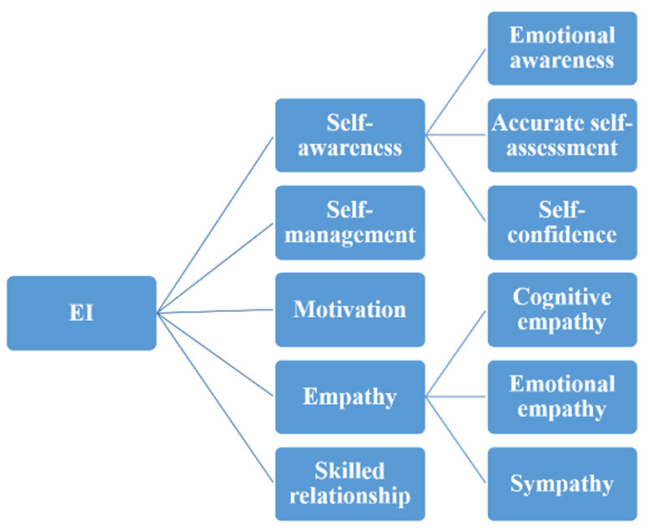

Figure 1. Factors determining EI

Adapted from Goleman 2003/ Goleman 2011/ Emmerling/Goleman 2005.

The second factor determining EI is self-management. Self-management refers to the capacity to manage oneself effectively. This can be, for example, a mature and effective way of coping with disquieting or frightening emotions such as fear of failure (Goleman, 2003).

The third factor, motivation represents a further important aspect of EI (Emmerling \& Goleman, 2005). According to Goleman, individuals with great EI tend to be highly motivated by their internal needs and objectives. Moreover, individuals that possess this aspect of EI demonstrate enthusiasm for their tasks and for new challenges, and an optimism despite the obstacles and defeats they face (Goleman, 2015).

The fourth factor is empathy which describes the ability to recognise and to understand feelings that other individuals have (Goleman, 2003). There are three different forms of empathy. The first form, cognitive empathy, enables a person to understand how others perceive matters. The second form is emotional empathy. It allows an individual to perceive how others feel. The third form of empathy is what we colloquially call sympathy, implying the ability to assist the suffering of others (Goleman, 2011). Combining the four factors above results in the domain of skilled relationships (Goleman, 2003). When leaders have mastered these factors and having the EI competencies to help individuals as well as groups to succeed they can achieve a superior performance (Goleman, 1998).

A further important aspect of EI research is the engagement with our rapidly changing understanding of neurosciences and how they contribute to effective leadership. Scholars have worked to explain how EI develops and occurs in our brains and what effects it has. First, it is relevant to emphasise that our brain is in constant flux including throughout adulthood. As reported by Goleman, "the neuroplasticity of the brain shapes itself according to repeated experiences" (Goleman, 2003). Neuroplasticity describes the "brain's capacity to react, therefore its capacity to reorganize itself through new connections or by disconnecting certain neural paths" (Pascale, 2018). Moreover, the different areas that exist in the human brain have each a particular function and are in permanent interaction with each other (Pascale, 2018). However, the areas of the brain assisting in the development of EI represent the last circuitry to be anatomically formed (Goleman, 2003). Its origin lays in the area of the limbic brain (Pascale, 2018). This emotional brain area learns and alters through experience and consistent feedback. For example, to turn positive motives into patterns of habit, a certain behaviour must be implemented and repeated regularly (Psionline, 2019). The brain neocortex is where awareness occurs, while the implementation and emotional feedback occur in the limbic system (Psionline, 2019) and the prefrontal cortex are relevant to EI. The Amygdala, a key part of the limbic system, records our emotional reactions and experiences, and can expand under certain situations into the prefrontal cortex (Goleman, 1998). These neural connections may, for instance, result in what is loosely called "gut feeling" or heuristics to help in decision-making (Goleman, 1998). 


\section{Correlation Emotional Intelligence, Leadership and Gender}

\subsection{Women's Leadership}

The percentage of women in leadership roles is increasing and advancing towards gender parity as measured by the four scales of economic participation, educational attainment, health and survival, and political empowerment (World Economic Forum, 2019). Nonetheless, the number of female leaders is still low when compared to male leaders (Lopez-Zafra et al., 2012). This phenomenon can, for example, be identified in politics which displays "the worst-performing-dimension" for women (World Economic Forum, 2019). For example, the Nordic countries dominate rankings in gender equality and are considered as pioneers in advancing equality between women and men. Despite this progress and their leading performance, from 2017 to 2019 only $41.4 \%$ of members of parliament were women in these countries (Jürgensen, 2020). The average percentage of women on the boards of the largest listed enterprises in the Organisation for Economic Cooperation and Development (OECD) countries was $25,5 \%$ in 2019 (OECDStat, 2020).

The possible ongoing reasons for women's underrepresentation in leadership roles may include the difficulties and prejudice that women still face when entering leading positions. Researchers describe an invisible divider, the so-called glass ceiling, which prevents women from attaining leadership roles (Zanville, 2001). Women, thus, face challenges such as gender stereotypes, i.e. the distribution of roles, insufficient access to professional networks or concerns about women's eligibility for leadership positions (Dezső et al., 2016). According to Eagly and associates (1992), "people do evaluate female leaders slightly more negatively than equivalent male leaders" (p.13). One reason could be that women possess personality traits such as selflessness, warmth or kindness, which are perceived to not correlate with effective leadership (De Jonge, 2015). Men, meanwhile, are considered to be confident, competitive, and aggressive (Holmes, 2017).

However, scholars (Eagly et al., 1972; Hudson \& Williamson, 2002; Foss et al. 2021; Keohane, 2010) suggest that women often exhibit a different leadership style. As Eagly and associates (1972) demonstrate, women tend to use a more democratic or participative leadership style than men. Thus, presenting a democratic or participatory style is perceived as a feminine way of leading, whereas men tend to be more autocratic (Hudson \& Williamson, 2002). Participative leadership is seen an efficient way to facilitate effective leadership and organisational outcomes (Lopez-Zafra et al., 2012). According to Foss and associates (2021) a more female leadership style that includes being communicative and inclusive contributes to the innovation level. Northouse (2010) demonstrated that there are leadership styles that are either considered as masculine or feminine leading styles. Hence, women are considered to use a different, more female, way of leading (Keohane, 2010). Consequently, Eagly and associates (1972) state that women deploying a more stereotypically feminine leadership style receive a more advantageous evaluation on their leadership effectiveness. On the contrary, women who exhibit a masculine style are assessed lower.

Despite this rather stereotypical differentiation between feminine and masculine leadership style, Keohane (2010) explains that it is "not true that all women in all positions of leadership behave in ways that are "typically female". However, it becomes evident that enhancing women's leadership increases the number of potential competent candidates and can broaden the group perspectives in more effective decision-making and task design (De Jonge, 2015). Moreover, Dezsö and Ross (2012) explain "that female representation in top management brings informational and social diversity benefits to the top management team" (p. 1072). Glass and associates (2016) further suggest that gender diversity on boards encourages increased environmentally friendly actions whereas Foss and associates (2021) incline that female representation in management or leadership teams positively contribute to innovation processes.

Furthermore, women are inclined to demonstrate a transformational leadership approach (Lopez-Zafra et al., 2012). As already mentioned, transformational leadership focuses on interactions between the leader and subordinates and seeks for a greater goal accomplishment than expected (Schaubroeck et al., 2007). Transformational leadership describes four elements for effective leadership including idealised influence, inspirational motivation, intellectual stimulation, and individualised consideration (Northouse, 2010). According to these components, leaders should act as role models with a vision, to motivate and inspire, encourage followers to be innovative and supportive, and listen to subordinates (Bass \& Steidlmeier, 1999). Thus, effective women leaders inspire, distribute tasks based on subordinates' strengths, and are involved emotionally (Science of People, n.d.).

\subsection{Emotional Intelligence and Leadership}

Is there a correlation between EI and effective leadership outcomes? According to psychologist Daniel Goleman, "great leaders work through the emotions" (Goleman et al., 2013). John D. Mayer and David Caruso (2002) described effective leadership by claiming that "leaders who can use feelings will have advantages". Hence, EI is a 
strong predictor of effective leadership (Emmerling \& Goleman, 2005). Emotions as well as cognition are involved in decision-making processes. Moreover, they include the emotional competencies of self-awareness, affective self-regulation, motivation, empathy, and interpersonal functioning (Emmerling \& Goleman, 2005). These aspects of EI are inter alia significant for the organisational framework of a group. Additionally, the capacity to handle distressing emotions and to empathise with other's emotions helps perform better, for instance, in evaluation (Nadler \& Lowery, 2009).

There are various explanations for the relevance of EI in predicting effective leadership outcomes. They include, for example, the Open Loop theory which presents a neuroscientific explanation predicated on the limbic system being deeply relevant to EI as the emotional center of the human brain (Pionline, 2019). The Open Loop presents the nature of the limbic system and displays that the inner state of individuals is related to external sources (Goleman et al., 2013). Laughter is an example, in which a person smiles, the person next to him or her tends to laugh as well (Goleman et al., 2013). Consequently, an individual can change not only one person's mood, but also his or her physiology, through changes in the hormone levels, cardiovascular functions, or positive immune system responses (Reeves, 2005). This physiological alteration in by an external person is called mirroring (Goleman et al., 2013). As a result, the open-loop limbic system demonstrates how important EI can be to the leader's capability to handle their own and other's emotions. Moreover, it can be seen as an advantage for which the leader assumes the emotional guidance of a group (Goleman et al., 2013). Moreover, the mood of an individual is decisive for his effectiveness since a good mood improves neural abilities. These enable leaders to effectively work on goal accomplishment (Goleman et al., 2013).

The concept of Emotional Hijacking explains that, on the contrary, negative emotions are able to disrupt work. In response these negative emotions can also decrease a person's EI (Goleman et al., 2013). Consequently, an effective leader knows how to guide emotionally, to collaborate in the group by increasing the group's satisfaction and collaborative mood, and to handle negative emotions so that they do not result in emotional hijacking (Note 1) (Farooqi, 2008). Finally, the EI in leaders could further be displayed by analysing, for example, its correlation with organizational outcomes at the individual leader level or the team or working group levels. However, it is important to understand the relevance of the aspects of EI self-awareness, self-regulation, motivation, empathy, and skilled relationship in effective leadership.

The insights gained above can also applied to several leadership theories, where emotional involvement is considered as a decisive element to effective and competent leadership. For example, "EI contributes to a strong transformational leadership" (Condren et al., 2006). One of the factors of Transformational Leadership presented by Walumba and Associates is motivational inspiration. Within this motivational inspiration, these scholars described emotions, especially the emotional appeal, as indispensable to motivate and inspire subordinates so that they could raise their potential to its fullest and achieve higher goals than expected (Northouse, 2010).

\subsection{Emotional Intelligence and Gender}

The following section will address whether there is a relationship between EI and gender, more precisely, whether women are more emotionally intelligent than men. Several scholars have focused on this issue and worked on finding biological, neuroscience, and psychological evidence to demonstrate a women's predisposition to EI. As Fernández-Berrocal and associates (2012) state, Simon Baron Cohen outlines biological arguments to demonstrate a women's greater emotional capabilities. He argues that individuals either have an extreme female brain or an extreme male brain. Women with an extreme female brain exhibit greater empathy, whereas men have advantages in understanding and constructing complex systems (Fernández-Berrocal et al., 2012). Consequently, due to their empathy, women with an extreme female brain are considered to have a higher EI than men with an extreme male brain (Condren et al., 2006). Furthermore, scholars have tried to identify socialization (Note 2) as an important reason for women's tendency to possessing high EI., Sánchez-Núnez and associates (2008) claim that women tend to be more emotionally expressive and are better at understanding the emotions of others. This may arise from childhood where girls are rather involved with and are encourages to discuss and reflect on their feelings (Fernández-Berrocal et al., 2008).

However, more recently, scholars have not found that gender differences concerning EI do exist (Nadler \& Lowery, 2009) and indeed suggested that "empathy is influenced by contextual factors and can be systematically biased by gender roles and stereotypical beliefs" (Loeffler \& Greitemeyer, 2021, p.1). Therefore, some gender psychologists emphasise that "gender by itself does not have explanatory power in absence of other variables" (Fernández-Berrocal et al., 2012). Hence, while it is possible to give vague assertions that may describe an average women's EI, this needs to be contextualized and interpreted and customized to women and men. Consequently, despite our socially and culturally based perceptions of women's emotions, it is evident that men have similar 
predispositions to possess EI. Daniel Goleman argues that EI is not genetically determined (Goleman, 1998). Explaining that women are, for instance, better in showing emotional empathy, and social skills as compared to men (Goleman, 1998). Men, on the other hand, are better on dissolving negative emotions, being self-confident and optimistic (Goleman, 2003). These differences are considered by Goleman as strong and weak points, respectively that do not necessarily apply to each individual (Goleman, 1998). Consequently, a man can have more empathy than a woman; or a woman may be more self-confident than a man (Goleman, 2011). Besides, by emphasising that EI and its competences can be learned, Daniel Goleman demonstrates that individual, regardless of their gender, can work on improving their emotional skills and EI (Goleman, 2003) and notes that "unlike IQ, which changes little after our teen years, EI seems to be largely learned, and it continues to develop as we go through life and we learn from our experiences- our competence in it can keep growing" (Goleman, 1998, p.7).

Finally, as Goleman stated - "neither is better - both have advantages" (Goleman, 2011) - women and men have a predisposition to EI and the gender by itself does not necessarily result in better empathy or a higher self-confidence. Especially, when it comes to learning EI, men and women have the same opportunities to acquire a greater EI through experience.

\section{Discussion: Emotional Intelligence Enhancing Women's Leadership}

For a long time, masculinity was seen as a predicting trait for effective leadership. Although the number of women in management positions is increasing, an underrepresentation can still be observed. There are of course many factors that contribute to this dearth of women at senior levels. For centuries, there have been broad, cultural biases against women and stereotypes die slowly. People have long believed that many women elect not to aspire to the highest ranks of the organization and take themselves out of the running. Lots of research has shown that unconscious bias places a significant role in hiring and promotion decisions, which also contributes to the lower number of women in key positions.

However, today's successful female leaders demonstrate that femininity can also be considered an important factor. We discussed women's leadership - their underrepresentation in leadership positions, female leadership styles as well as possible advantages that result from gender diversity in leadership positions -, the correlation between EI and leadership effectiveness, and the link between EI and gender. We now understand that women as well as men have the same prerequisites for (learning) EI. Besides, we found that EI is an essential determinant for effective leadership as well as an integral element of the transformational leadership approach. As a result, it becomes clear that women have the same potential to become effective and successful leaders by developing and enhancing their EI. Women possessing a tendency to express and understand emotions with a high EI or with a feminine leadership behaviour attribute should focus on these competencies, rather than trying to adapt to a bossy or a so-called male leadership behaviour. It is evident that women, as well as men, have the potential to become competent leaders. The transformational leadership style, which several women tend to use, emphasizes that emotional involvement helps to motivate, inspire, support subordinates, by sharing a common vision and identity (Science of People, n.d.). Therefore, involving women in leadership positions gives new perspectives to all aspects of leadership.

Consequently, it is important that every individual, regardless of their gender, socialisation, or other predispositions, should aim to increase EI. Moreover, although several members of society might perceive women as too emotional or not made of the "right stuff" to lead, a long-held bias- women should work on becoming more self-aware of their strengths by developing empathy and self-regulation, and on enhancing their social skills.

\section{Conclusion}

Leadership roles were perceived for a long time to be better suited to men than women, as women were stereotypically considered to be more emotional and empathic than men. However, since EI is recognized as an important determinant of effective leadership, the question of whether women do indeed have an advantage over men in this respect arises. And thus, whether their, stereotypically known, emotional and empathic nature qualifies them for leadership positions. Therefore, the aim of this paper was to examine to what extent EI as an important determinant of effective leadership can be an asset for women's leadership competencies. However, this literature review demonstrates that leadership competencies and EI can be acquired by women as well as by men, and that women in leadership positions are perceived as being every bit as effective as men.

A key limitation of the study is the complexity of measuring leadership competencies or styles as well as EI in terms of gender. As already mentioned before, gender in general cannot be used as a reference without any other variable. Consequently, as Goleman (2011) cites Ruth Malloy, when it comes to leaders in the top ten percent of business performance, it becomes evident that "gender differences in EI abilities wash out: The men are as good as the women, the women as good as the men, across the board". Besides, the qualitative method of this paper presents a further limitation since, although it employs previous research to understand the link between EI, 
leadership and gender, it does not sufficiently assess the question. For that reason, a recommendation for further research on this topic is to conduct a quantitative study on the impact of EI on enhancing women's leadership competencies as well as their access to leadership positions. Specifically, assess EI of women in these positions and of aspiring female leaders. How do the results rank in comparison to the EI of their male counterparts? Additionally, it would be interesting to investigate whether the role of EI and women's leadership vary in value in different professional contexts.

Finally, EI enables male as well as female leaders to motivate and inspire groups of individuals to enhance creativity and productivity. This happens through role modelling following high moral standards to reinforce the group identity. Society needs to support women entering leadership positions, which will contribute to society greater effectivity and increase the representation of women.

\section{References}

Bass, B., \& Steidlmeier, P. (1999). Ethics, character, and authentic transformational leadership behaviour. Leadership Quarterly, 10(2), 181-217. https://doi.org/10.1016/S1048-9843(99)00016-8

Bennis, W. G., \& Nanus, B. (1985). Führungskräfte: die vier Schlüsselstrategien erfolgreichen Führens. Campus.

Bolten, G. (2020, Match 18). Kalkutta: Mutter Teresa. Retrieved from https://www.planet-wissen.de/kultur/asien/kalkutta_stadt_der_freude/pwiemutterteresa100.html

Carli, L. L., \& Eagly, A. H. (2011). Gender and Leadership. In Bryman, Alan (Ed.), The SAGE handbook of leadership (1. publ..), 103-113.

Carlyle, T. (1872). On heroes, hero-worship and the heroic in history. Chapman \& Hall.

Citaku, F., Violato, C., Beran, T., Donnon, T., Hecker, K., \& Cawthorpe, D. (2012). Leadership competencies for medical education and healthcare professions: population-based study. BMJ Open, 2(2). https://doi.org/10.1136/bmjopen-2012-000812

Condren, T., Martin, B. N., \& Hutchinson, S. (2006). What does Emotional Intelligence and Gender have to do with Leadership Effectiveness...Or does it. Advancing Women. Retrieved from http://www.advancingwomen.com/awl/summer2006/Condren_Martin_Hutchinson.html

Debebe, G. (2019). Women's leadership development: caring environments and paths to transformation. Routledge. https://doi.org/10.4324/9781315687452

De Jonge, A. (2015). The Glass Ceiling in Chinese and Indian Boardrooms. Chandos. https://doi.org/10.1016/C2013-0-16842-0

Dezsö, C. L., \& Ross, D. G. (2012). Does female representation in top management improve firm performance? A panel data investigation. Strategic Management Journal, 33(9), 1072-1089. https://doi.org/10.1002/smj.1955

Dezső, C. L., Ross, D. G., \& Uribe, J. (2016). Is there an implicit quota on women in top management? A large-sample statistical analysis. Strategic Management Journal, 37(1), 98-115. https://doi.org/10.1002/smj.2461

Eagly, A. H., Makhijani, M. G., \& Klonsky, B. G. (1992). Gender and the Evaluation of Leaders. Psychological Bulletin, 111(1), 3-22. https://doi.org/10.1037/0033-2909.111.1.3

Emmerling, R. J., \& Goleman, D. (2005). Leading with Emotion. Leadership Excellence, 22(7), 9-10.

Farooqi, S. (2008). Emotional Hijacking: The trigger to an unhealthy mind. Life and Psychology. Retrieved from http://www.lifeandpsychology.com/2008/11/emotional-hijacking.html

Fernández-Berrocal, P., Cabello, R. C., Castillo, R., \& Extremera, N. (2012). Gender differences in Emotional Intelligence: The mediating effect of age. Behavioural Psychology, 20(1), 77-89. Retrieved from https://www.researchgate.net/publication/257236324_Gender_differences_in_emotional_intelligence_The_ mediating_effect_of_age

Foss, N., Lee, P. M., Murtinu, S., \& Scalera, V. G. (2021). The XX factor: Female managers and innovation in a cross-country setting. The Leadership Quarterly, 101537. https://doi.org/10.1016/j.leaqua.2021.101537

Goleman, D., Boyatzis, R. E., \& McKee, A. (2013). Primal Leadership: Unleashing the Power of Emotional Intelligence. Harvard Business Review Press.

Goleman, D. (1998). Working with Emotional Intelligence. Bantam Books. 
Goleman, D. (2003, May 11). Emotional Intelligence: What is it and do men or women have more of it. Big Think. Retrieved from https://bigthink.com/videos/daniel-goleman-introduces-emotional-intelligence

Goleman, D. (2011). Are women more emotionally intelligent than men. Psychology Today. Retrieved from https://www.psychologytoday.com/us/blog/the-brain-and-emotional-intelligence/201104/are-women-more-e motionally-intelligent-men

Goleman, D. (2015). What makes a leader. In Harvard Business Review (Ed.), HBR's 10 Must Reads: On Emotional Intelligence (pp. 1-22).

Grint, K. (2011). A History of Leadership. In Bryman, Alan (Ed.), The SAGE handbook of leadership (1. publ..), (pp. 3-14).

Harrison, E. G. (2019). Feminism comes of age in Finland as female coalition takes the reins. The Guardian. Retrieved

from https://www.theguardian.com/world/2019/dec/14/feminism-finland-gender-equaity-sanna-marin

Holmes, J. (2017). Leadership and Change Management: Examining Gender, Cultural and "Hero Leader" Stereotypes. In Ilie, Cornelia/ Schnurr, Stephanie (Eds.), Challenging Leadership Stereotypes Through Discourse: Power, Management and Gender (pp. 15-43). https://doi.org/10.1007/978-981-10-4319-2

Hudson, M. B., \& Williamson, R. D. (2002). Women transitioning into Leadership: Gender as both Help and Hindrance. Advancing Women. $\quad$ Retrieved http://www.advancingwomen.com/awl/fall2002/HUDSON.html

Jürgensen, A. L. (2020). Women in politics in the Nordic countries- Statistics and Facts. Statista. Retrieved from https://www.statista.com/topics/6092/women-in-politics-in-nordic-countries/

Keohane, N. O. (2010). Thinking about Leadership. Princeton University Press.

Khan, Z. A., Nawaz, A., \& Khan, I. (2016). Leadership Theories and Styles: A Literature Review. Journal of Resources Development and Management, 16(ns), 1-7. Retrieved from https://www.researchgate.net/publication/293885908_Leadership_Theories_and_Styles_A_Literature_Revi ew

Loeffler, C. S., \& Greitemeyer, T. (2021). Are women the more empathetic gender? The effects of gender role expectations. Current Psychology. https://doi.org/10.1007/s12144-020-01260-8

Lopez-Zafra, E., Garcia-Retamero, R., \& Martos, M. P. M. (2012). The relationship between Transformational Leadership and Emotional Intelligence from a gendered approach. The Psychological Record, 62(ns), 97-114. https://doi.org/10.1007/BF03395790

Lord, R. G., \& De Vader, C. L., \& Alliger, G. M. (1986). A Meta-Analysis of the Relation Between Personality Traits and Leadership Perceptions. Journal of Applied Psychology, 71(3), 402-410. https://doi.org/10.1037/0021-9010.71.3.402

Luthans, F., \& Avolio, B. (2003). Authentic Leadership Development: a positive developmental approach. In Cameron, K. S., Dutton, J. E., \& Quinn, R. E. (Eds.), Positive Organizational Scholarship (pp. 241-261).

Mann, R. D. (1959). A review of the relationships between personality and performance in small groups. Psychological Bulletin, 56(4), 241-270. https://doi.org/10.1037/h0044587

Mayer, J. D., \& Caruso, D. (2002). The effective leader: Understanding and applying emotional intelligence. IVEY Business Journal, 66, 1-5.

Nadler, J. T., \& Lowery, M. R. (2009). Emotional expression, gender, personality and workplace appropriate behaviors. In Härtel, C. E. J., Ashkanasy, N. M., \& Zerbe, W. J. (Eds.), Emotions in groups, organisations and cultures (pp. 23-43).

Northouse, P. G. (2019). Leadership: theory and practice (5th ed.). SAGE.

OECD.Stat. (2020). Employment: Female share of seats on boards of the largest publicly listed companies. OECD. Retrieved from https://stats.oecd.org/index.aspx?queryid=54753

Pascale, V. (2018). Neurofeedback: Tools, Methods and Application. Elsevier. https://doi.org/10.1016/C2017-0-02193-6

Psionline. (2019). Neuroscience of Emotional Intelligence. Psionline. Retrieved from https://www.psionline.com/en-gb/emotional-intelligence/neuroscience 
Reeves, A. (2005). Emotional Intelligence: Recognizing and Regulating Emotions. AAOHN Journal, 53(4), 172-176. https://doi.org/10.1177/216507990505300407

Ruderman, M. N., Ohlott, P. J., Panzer, K., \& King, S. N. (2002). Benefits of Multiple Roles for Managerial Women. Academy of Management Journal, 45(2), 369-386. https://doi.org/10.2307/3069352

Sánchez-Núnez, T., Fernández-Berrocal, P., Monatnes, J., \& Latorre, J. M. (2008). Does Emotional Intelligence depend on gender? The socialization of emotional competencies in men and women and its implications. Electronic Journal of Research in Educational Psychology, 6(2), 455-474.

Schaubroeck, J., Lam, S. S. K., \& Cha, S. E. (2007). Embracing Transformational Leadership. Journal of Applied Psychology, 92(4), 1020-1030. https://doi.org/10.1037/0021-9010.92.4.1020

Science of People. (n.d.). Women in Leadership. 6 Strategies for Female Managers. Science of People. Retrieved from https://www.scienceofpeople.com/women-in-leadership/

Toor, S., \& Ofori, G. (2008). Leadership Versus Management: How they are different, and why. Leadership and Management in Engineering, 8(2), 61-71. https://doi.org/10.1061/(ASCE)1532-6748(2008)8:2(61)

Walker, S. (2020). Covid-19 was a Leadership Test. It Came Back Negative. The Wall Street Journal. Covid-19 was a Leadership Test. It Came Back Negative. - WSJ

World Economic Forum. (2019). Mind the 100 Year Gap. World Economic Forum. Retrieved from https://www.weforum.org/reports/gender-gap-2020-report-100-years-pay-equality

Zanville, R. L. (2001). A Quantitative Analysis of the Personal Characteristics and Workplace Experiences of Women and Men as Professional and Community Leaders. Advancing Women. Retrieved from http://www.advancingwomen.com/awl/winter2001/zanville/zanville.html

\section{Notes}

Note 1. Emotional hijacking is a state when an individual's cognitions are overpowered by his/her emotions. It is usually referred to in the context of aggression or fearfulness (Farooqi 2008).

Note 2. Socialisation is the process whereby one acquired the knowledge skills and dispositions needed to perform a role (Hudson/ Williamson 2002).

\section{Copyrights}

Copyright for this article is retained by the author(s), with first publication rights granted to the journal.

This is an open-access article distributed under the terms and conditions of the Creative Commons Attribution license (http://creativecommons.org/licenses/by/4.0/). 